\title{
Correction to: The role of city geometry in determining the utility of a small urban light rail/tram system
}

\section{Michael Mc Gettrick ${ }^{1}$}

Accepted: 12 June 2020 / Published online: 13 July 2020

(c) Springer-Verlag GmbH Germany, part of Springer Nature 2020

\section{Correction to: Public Transport 12, 233-259 (2020) https://doi.org/10.1007/s12469-019-00226-9}

I wish to correct a small but nonetheless important error in my paper "The role of city geometry in determining the utility of a small urban light rail/tram system", Mc Gettrick, M., Public Transport, Vol. 12, pp. 233-259, (2020), DOI https://doi. org/10.1007/s12469-019-00226-9.

The equation at the beginning of Sect. 4.4, and also Eq. (45) at the end of Appendix B, should both be replaced by

$$
\mathrm{IF}=\frac{23}{72}
$$

Furthermore, a few calculations leading up to this expression in Appendix B should be changed, specifically:

1. Appendix B, Eq. (41):

- Replace $a^{4}(1+6 \ln 2) / 9$ by $a^{4}(1-2 \ln 2 / 3)$.

- Replace $2 \mathrm{a}^{2}(1+6 \ln 2) / 9$ by $2 a^{2}(1-2 \ln 2 / 3)$.

2. Appendix B, Eq. (44):

- Replace $4(1+6 \ln 2) / 3$ by $12-8 \ln 2$.

- Replace $a^{2}(7+24 \ln 2) / 18$ by $23 a^{2} / 18$.

The original article can be found online at https://doi.org/10.1007/s12469-019-00226-9.

Michael Mc Gettrick

michael.mcgettrick@nuigalway.ie

1 School of Mathematics, Statistics and Applied Mathematics, National University of Ireland Galway, Galway, Ireland 
Publisher's Note Springer Nature remains neutral with regard to jurisdictional claims in published maps and institutional affiliations. 